\title{
Descriptions of Two New Species of the Genus Brevipalpus (Acari: Tenuipalpidae) Donnadieu from Punjab, Pakistan
}

\author{
Mansoor-ul-HASAN ${ }^{1}$, Waqas WAKIL ${ }^{2}$, Faiza BASHIR $^{3}$ and Y. J. KWON ${ }^{4}$ \\ ${ }^{1}$ Department of Agric. Entomology, University of Agriculture, Faisalabad, Pakistan \\ ${ }^{2}$ Department of Entomology, University of Arid Agriculture, Rawalpindi, Pakistan \\ ${ }^{3}$ Department of Zoology, University of Arid Agriculture, Rawalpindi, Pakistan \\ ${ }^{4}$ College of Agricultural \& Life Sciences, Kyungpook National University, Daegu, Korea
}

(Received 21 September 2004; Accepted 19 April 2005)

\begin{abstract}
Two new species of the genus Brevipalpus are described and figured from Gujranwala Division of Punjab Province in Pakistan: B. khalidae n. sp. from Trianthema partulacastrum and Cannabis sativa; and $B$. hamzaii n. sp. from Helianthus annuus.
\end{abstract}

Key words: new species, Brevipalpus khalidae, B. hamzaii, Pakistan

\section{INTRODUCTION}

A good number of works on Pakistani Tenuipalpidae have been published. The major works are those by Ahmad and Akbar (1984), Akbar and Aheer (1990, 1994), Chaudhri (1972), Chaudhri et al. (1974), Chaudhri and Akbar (1985), Hasan et al. (2002, 2003) and Rui et al. (2003). Up to the present, 96 species belonging to this family, including 36 species of the genus Brevipalpus, were previously recorded from this country. However, the tenuipalpid fauna still remain to be explored in a lot of areas of Pakistan.

In this paper two new species of Brevipalpus are described and figured from Gujranwala Division of Punjab, Pakistan. The setal nomenclature follows that of Lindquist (1985). The measurements are given in micrometers $(\mu \mathrm{m})$. The specimens examined, including the type series of the new species, are preserved in the Acarology Research Laboratory, Department of Agricultural Entomology, University of Agriculture, Faisalabad, Pakistan.

\section{Brevipalpus khalidae $\mathrm{n} . \mathrm{sp}$.}

(Fig. 1, A-D)

Female: Body (excluding rostrum) 260 long, 165 wide.

Dorsum (Fig. 1A). Rostrum reaching the base of femur I. Rostral shield deeply notched medially, with 1 conical median and 2 ancillary lobes on each side (Fig. 1D). Palpus 4segmented, distal segment with 1 eupathidium and 2 simple setae, segments II and III, with 1 and 2 barbed setae, respectively (Fig. 1C). Prodorsum with areolae medially, longitudinal

*Corresponding author: e-mail: waqaswakeel@hotmail.com 
striae mediolaterally, the striae fading away laterally. Prodorsal setae slightly lanceolate, serrate; lengths: $v 2$ 10, sc1 17.5, sc2 7.5. Opisthosoma with broken longitudinal striae medially and mediolaterally, a long ridge mediolaterally upto caudal end; lateral area with faint striations directed marginally. A wavy, broken transverse line slightly posterior to seta $c 1$. Opisthosomal dorsocentral setae smooth; lengths: $c 1$ 10, $d 16.25$, el 7.5. Dorsolateral opisthosomal setae 6-paired, slightly lanceolate, serrate, shorter than distances between their

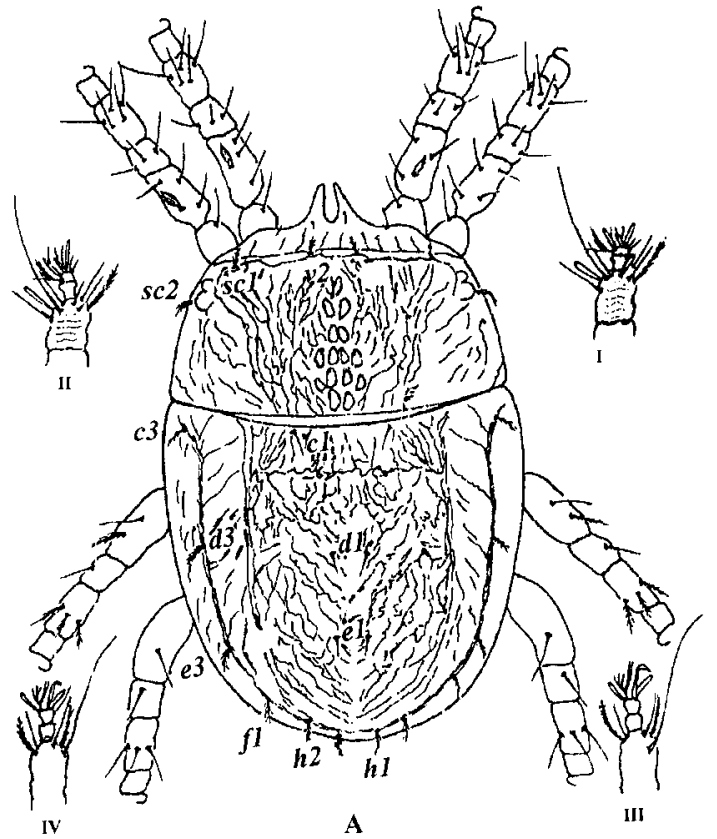

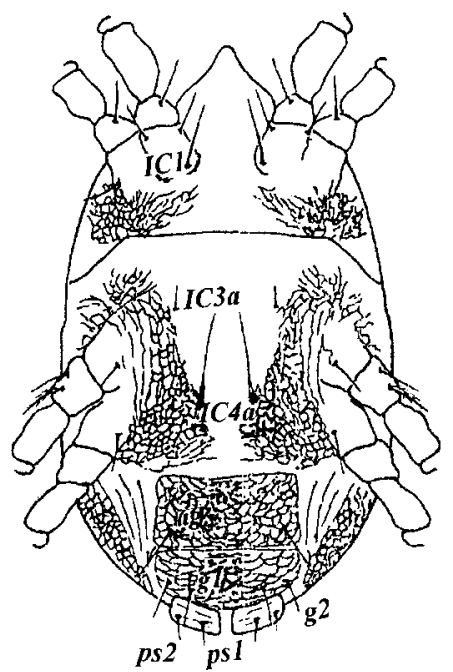

B
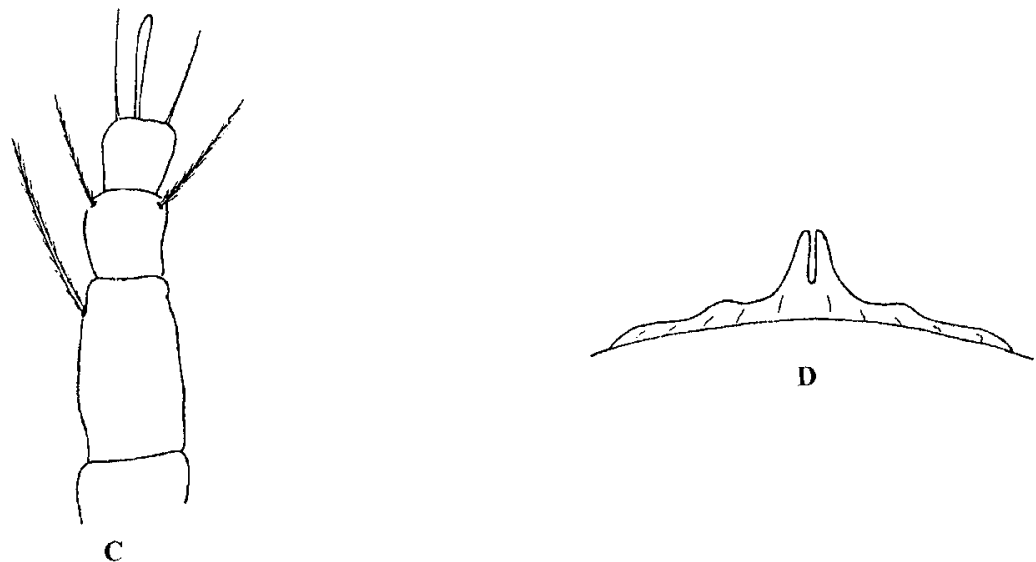

D

Fig. 1. Brevipalpus khalidae n. sp. (우). A, dorsal side; B, ventral side; C, palpus; D, rostral shield. 
bases; lengths: $c 35, d 3=e 3=10, f 18, h 26, h 111$ (Fig. 1A).

Venter. Venter with reticulations at base of coxa II, lateral to apodemes of coxa II, anterior to coxa III, lateral to coxae III and IV, and lateral to ventral shield; reticulations anterior to ventral shield not meeting medially. All ventral body setae smooth; IC4a shorter than distance to base of IC 3a; lengths: ICla 33, IC 3a 9, seta IC4a 63, ag 13, g1 13, g2 15, ps 1 10, ps2 6. Ventral shield reticulate. Genital shield with striations giving the appearance of reticulations. Anal shield with a few transverse striae (Fig. 1B).

Legs. Leg segments wrinkled, number of setae on legs: coxae 2-2-1-1, trochanters 1-1$2-1$, femora 4-4-2-1, genua 3-3-1-1, tibiae 5-5-3-3, tarsi 8-8-5-5. Dorsal setae on femora I and II broadly lanceolate, serrate, subequal to the width of the respective segment. Tarsi I and II each with 2 sensory pegs (Fig. 1A).

Male. Not known.

Type series. Holotype female, from $3 \mathrm{~km}$ N. Gujrat, 17.07.1994 (Mansoor), on Trianthema partulacastrum L. ("Itsit"); 1 paratype female, with the same data; 1 paratype female from Wazirabad, 17.07.1994 (Mansoor), on Cannabis sativa L. ("Bhang").

Remarks. Brevipalpus khalidae n. sp. is close to B. phoenicis (Geijskes, 1939) (Pritchard and Baker, 1951) in the well developed striation with prominent areolae on the medial area of prodorsum, more or less longitudinal striations covering opisthosoma, and rougose pattern on ventral and genital shield, but differs from the latter in the ancillary lobes on each side of rostral shield, seta $I C 4 a$ not reaching the base of seta $I C 3 a$, the clear median area posterior to $I C 4 a$, and the smooth genital shield setae.

Moreover, B. khalidae n. sp. is closely related to B. spurcus Chaudhri, 1974. However, it can be separated from the latter on the basis of the following characters:

1. Rostral shield pitted, with 4 ancillary lobes on each side in spurcus, but striate with 2 ancillary lobes on each side in B. khalidae n. sp.

2. Prodorsum without any ornamentation medially in spurcus, but with thick-walled areolae in the new species.

3. Ventral shield with broken striae in spurcus, but with reticulations in the new species.

4. Genital shield with striae in spurcus, but, with reticulations longer than broad in the new species.

Etymology. The new species is named after the name of the senior author's wife.

\section{Brevipalpus hamzaii $\mathrm{n} . \mathrm{sp}$.}

(Fig. 2, A-D)

Female: Body (excluding rostrum) 241 long, 163 wide.

Dorsum. Rostrum reaching upto middle of femur I. Palpus with 1 eupathidium and 1 simple seta on distal segment (Fig. 2C). Rostral shield with faint striae, with 1 conical median and 3 ancillary lobes on each side (Fig. 2D). Prodorsum with reticulations irregular, thick-walled, fading away medially and laterally. Prodorsal setae serrate; lengths: $v 27, s c 1$ 8, sc2 11 (Fig. 2A). Opisthosoma with reticulations medially between setae $c l$ and $d l$, and mediolaterally; with transverse striae medially beyond setae $d l$ up to caudal end; with faint striae laterally. All dorsocentral opisthosomal setae slightly lanceolate, serrate; dorsolateral 
opisthosomal setae 6-paired; lengths: $c 1$ 6, $d 1$ 5, el 6, c3 4, $d 3$ 6, e3 6, fl=h2=h1=4 (Fig. 2A).

Venter. Venter with transverse striae posterior to coxae I and II, with reticulations mediad and laterad of apodemes of coxa II, and with reticulations surrounding entirely both ventral and genital shields and extending anteriorly, alongside coxae III and IV upto the level of setae IC $3 a$. Ventral body setae smooth except for seta $p s 1$ which is serrate. Lengths: ICIa 25, IC $3 a 10, I C 4 a$ 29, ag 6, gl 11, g2 8 and ps 19 . Ventral and genital shield with reticulations wider than long. Anal shield with a few transverse striae (Fig. 2B).

Legs. Leg segments wrinkled. Number of setae on legs: coxae 2-2-1-1, trochanters 1-1-

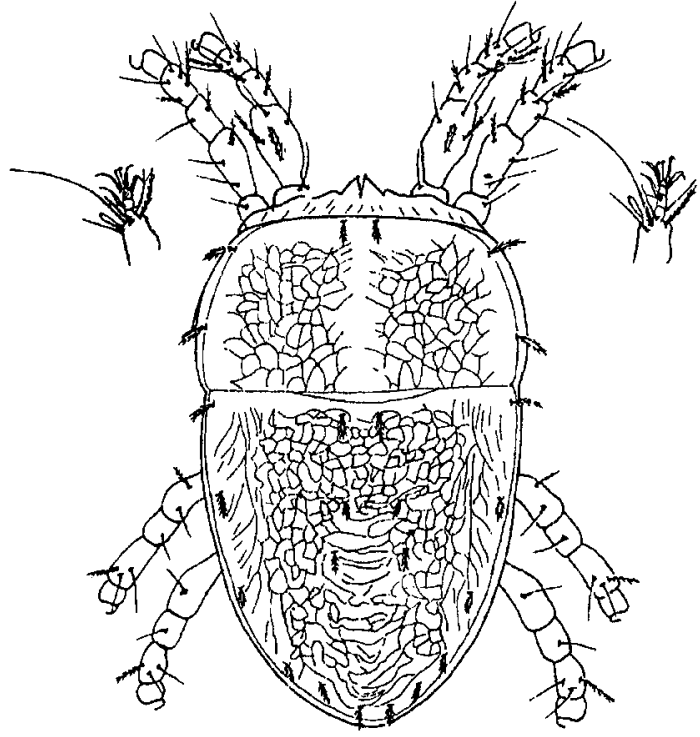

A

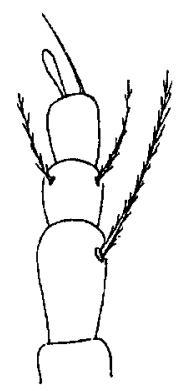

C

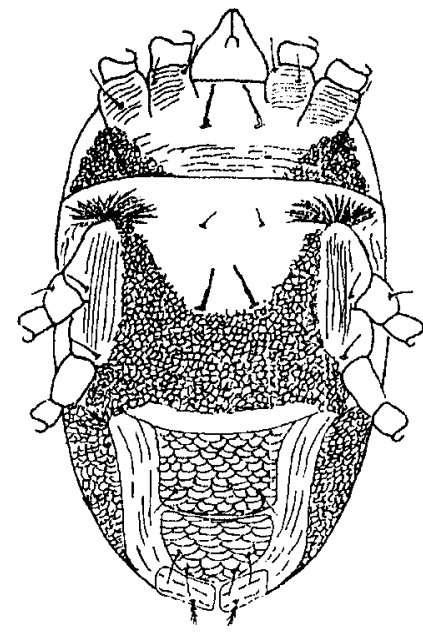

B

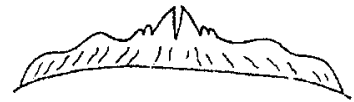

$\mathbf{D}$

Fig. 2. Brevipalpus hamzaii n. sp. (우). A, dorsal side; B, ventral side; C, palpus; D, rostral shield. 
1-0, femora 4-4-2-1, genua 3-3-1-1, tibiae 5-5-3-3, tarsi I and II with 6-7 setae, III and IV not clear. Femora I and II each with dorsal seta broadly lanceolate, serrate, shorter than half the width of the respective segment. Tarsi I and II each with 1 sensory peg (Fig. 2A).

Male. Not known.

Type series. Holotype female, from 2 miles E. Gujranwala, 10.06.1993 (Mansoor), on sunflower (Helianthus annuus L.); 2 paratype females, with the same data; 2 paratype females from Daska, 28.06.2002 (Mansoor), on the same host plant.

Remarks. Brevipalpus hamzaii n. sp. is close to B. origanum Baker, Tuttle and Abbatiello, 1975, but differs from the latter in the following points:

1. Rostrum short in origanum, but longer, reaching the middle of femur I in B. hamzaii n. sp.

2. Distal segment of palpus with 1 eupathidium and 2 setae in origanum, but with 1 eupathidium and 1 seta in the new species.

Brevipalpus hamzaii $\mathrm{n}$. sp. is also similar to B. ornantis Chaudhri and Akbar, 1985 on the basis of chaetotaxy of distal segment of palpus, the dorsal reticulations, the number of sensory pegs on tarsus II, but it differs from the latter in the following points:

1. Distal segment of palpus with a spatulate eupathidium in B. hamzaii n. sp. as opposed to a pointed eupathidium in ornantis.

2. Ventral shield reticulations wider than long in B. hamzaii n. sp. but as long as wide in ornantis.

3. Genital shield without any notch in the new species, but with a deep posterior notch in ornantis.

4. Anal shield with 1 pair of setae in the new species as opposed to 2 pairs in ornantis.

Etymology. The new species is named after the name of the senior author's son.

\section{REFERENCES}

Ahmad, I. and S. Akbar (1984) Two new species of mites of the genus Brevipalpus (Acarina: Tenuipalpidae) from Faisalabad. Pakistan Entomologist, 6: 1-6.

Akbar, S. and G. M. Aheer (1990) False spider mites (Acarina: Tenuipalpidae) from summer vegetables in Pakistan. Pakistan Journal of Agricultural Sciences, 27: 257-261.

Akbar, S. and G. M. Aheer (1994) Mite fauna of summer vegetables in Punjab-Pakistan. Pakistan Journal of Zoology, 26: 339-345.

Baker, E. W., D. M. Tuttle and M. J. Abbatiello (1975) The false spider mites of northwestern and north central Mexico. Smithsonian Contributions to Zoology, 194: 1-23.

Chaudhri, W. M. (1972) The genus Brevipalpus in Pakistan. I. Descriptions of six new species and redescription of one species with new records. Pakistan Journal of Zoology, 4: 53-88.

Chaudhri, W. M., S. Akbar and A. Rasool (1974) Taxonomic studies of the mites belonging to the families Tenuipalpidae, Tetranychidae, Tuckerellidae, Caligonellidae, Stigmaeidae and Phytoseiidae. University of Agriculture, Lyallpur, Pakistan, Technical Bulletin, 1: i-xiv+1-250.

Chaudhri, W. M. and S. Akbar (1985) Studies on the biosystematic and control of mites of field crops, vegetables and fruit plants in Pakistan. University of Agriculture Faisalabad, Pakistan, Technical Bulletin, 3: i-xiv+1-314.

Geijskes, D. C. (1939) Beiträge zur kenntnis der europäischen Spinnmôilben (Acari, Tetranychidae), mit besonderer Berücksichtigung der niederländischen Arten. Mededeelingen van de Landbouwhoogeschool te Wageningen, 42 : $1-68$.

Hassan, M., S. Akbar and M. Ashfaq (2002) False spider mites from Sunflower at Sheikhupura, Punjab—Pakistan. 
Pakistan Entomologist, 24: 53-59.

Hasan, M., F. Bashir, W. Wakil and M. Afzal (2003) Two new species of false spider mites of the genus Brevipalpus Donnadieu (Acarina-Tenuipalpidae) from Punjab-Pakistan. Acarologia, 43: 353-358.

Lindquist, E. E. (1985) Anatomy, phylogeny and systematics. 1.1.1. External anatomy. In: Spider Mites, Their Biology, Natural Enemies and Control, (eds., Helle, W. and M. W. Sabelis), 1A, pp. 3-28.

Pritchard, A. E. and E. W. Baker (1951) The false spider mites of California (Acarina: Phytoptipalpidae). University of California Publications in Entomology, 9: 1-94.

Rui, L. Y., M. Hasan and M. Ashfaq (2003) A new species of the genus Brevipalpus from mango trees in Shujaabad (Multan)-Pakistan. (Acari, Tenuipalpidae). Acta Zootaxonomica Sinica, 28: 645-647. 